\title{
Attachment and Crying in Patients with Medically Unexplained Somatic Symptoms
}

\author{
R. Jansman ${ }^{1}$ - M. M. E. Riem ${ }^{2}$ - S. Broekhuizen-Dijksman ${ }^{1}$ • C. Veth ${ }^{1}$ • E. Beijer ${ }^{1}$ • A. J. J. M. Vingerhoets ${ }^{2}$
}

Accepted: 29 October 2019 /Published online: 21 November 2019

(C) The Author(s) 2019

\begin{abstract}
Mentalization deficits and disturbances in emotional functioning may contribute to somatization in patients with medically unexplained somatic symptoms (MUSS). The present study aimed to increase understanding the psychological factors that contribute to somatization by examining associations between attachment, crying attitudes and behavior, and somatic symptoms in these patients. Attachment security was measured with the Experiences in Close Relationships Questionnaire in sixty-eight outpatients diagnosed with MUSS. Somatic symptom severity was measured with the RAND-36, crying frequency, and attitudes with the Adult Crying Inventory. Patients were asked to evaluate photographs of crying individuals in order to assess the perception of crying and empathic responses to crying. Attachment anxiety was significantly related to somatic symptom severity and negative attitudes toward crying. In addition, somatic symptom severity was related to a more negative attitude toward crying and less awareness of the interpersonal impact of crying on others. The association between attachment anxiety and somatic symptoms was, however, not mediated by crying or negative attitude toward crying. Neither were there significant associations between attachment, somatic symptoms, and empathic responses to crying. Altered attitudes to crying may stem from a history of insecure attachment experiences and may reflect maladaptive emotion strategies in MUSS patients.
\end{abstract}

Keywords Medically unexplained somatic symptoms $\cdot$ Attachment $\cdot$ Crying $\cdot$ Mentalization

\section{Introduction}

Medically unexplained somatic symptoms (MUSS) are physical symptoms that cannot be or are insufficiently explained by any known somatic dysfunctions after a thorough somatic examination. MUSS are a serious and frequent problem in both primary and secondary global health care $[24,46]$. In primary care, the prevalence of MUSS is as high as 3-10\% [24, 48]. Individuals with MUSS are difficult to treat, have high rates of

This article is part of the Topical Collection on Medicine

Electronic supplementary material The online version of this article (https://doi.org/10.1007/s42399-019-00180-4) contains supplementary material, which is available to authorized users.

M. M. E. Riem

m.m.e.hendricx@uvt.nl

1 Department of Psychiatry, Elisabeth-TweeSteden Hospital, Tilburg, the Netherlands

2 Department of Medical and Clinical Psychology, Tilburg University, Tilburg, the Netherlands disability, and increase annual health-care costs due to frequent visits to health-care professionals $[3,30]$.

Several psychological predisposing factors and mechanisms have been proposed to explain the development of MUSS. One of these putative predisposing factors that have received considerable attention is attachment style [34, 51, 58]. Infants are biologically predisposed to develop an attachment relationship with their caregiver. This attachment relationship is evolutionarily adaptive because it promotes parental proximity and increases the likelihood of protection (Bowlby 1969/1982). However, when parents reject their infant's attachment signals or respond in an inconsistent way, the child may form an insecure model of important others as unpredictably responsive or emotionally unavailable [1]. This insecure internal model may in turn influence later interpersonal behaviors and social relationships [6]. An anxiously attached individual, for example, may desire proximity to others while fearing rejection and abandonment, resulting in dependent and clingy interpersonal behavior. An avoidant attachment style, on the other hand, may result in keeping others at a distance since one has learned as a child that others are unreliable and dismissive $[16,17]$. The inclination to seek medical help during times of psychological distress as seen in MUSS can be regarded as a type of maladaptive insecure attachment behavior 
$[29,51]$. Indeed, an insecure attachment style has been found to be common in MUSS (50-88\%; [9]).

One type of behavior related to attachment is crying [37]. Crying can be seen as an attachment behavior in both childhood and adulthood [36]. In infancy, crying functions as a means to prevent separation from caregivers and getting needs, such as hunger, met [49]. Crying in adulthood has more complicated antecedents than, for example, hunger or pain but still functions as a means to communicate distress and elicit helping behavior in others [57]. Another hypothetical function of crying in adulthood is that it results in catharsis or relief after the crying episode (e.g., [7, 20]), although it should be noted that empirical data fails to provide strong support for this catharsis hypothesis because the emotional recovery may strongly depend on how others respond to the crying ([11, 8, 47]). The interpersonal function of crying has received more support, and recent studies indicate that adult crying stimulates caregiving responses and consequently facilitates social bonding ([22]). For example, visible tears have been shown to considerably impact the perceived need for support of the crier and the willingness to provide comfort $([26,56])$.

Research indicates that (insecure) attachment is linked to crying behavior [14, 31]. More specifically, anxious attachment has been related to frequent, exaggerated crying and a more positive view of crying $[14,31,35]$, which may reflect the need to maximize attachment behavior in order to elicit help. Avoidantly attached individuals, on the other hand, are more prone to suppress and reduce crying behavior and have more negative views of crying [14, 31, 35]. This might stem from punishment or rejection in response to crying in infancy. An avoidantly attached individual desires self-reliance and emotional distance from others and may, therefore, tend to inhibit crying behaviors. This may, in turn, impede the communication of distress and influences interpersonal functioning. Atypical crying behaviors have also been associated with mentalization deficits or alexithymia [10]. Atypical crying thus seems to reflect abnormal emotional functioning and may also be related to psychopathology. Indeed, atypical crying behaviors have been observed in eating disorders [33] and borderline personality disorder [40].

The present study was designed to increase our understanding of the emotional functioning in patients with MUSS. To that end, we examined associations between attachment, crying frequency (during the last 4 weeks), crying attitudes, and MUSS severity. Since individuals with more severe MUSS have higher rates of insecure attachment [45], we expected this to be related to crying behavior and attitudes toward crying. More specifically, we anticipated that individuals with more severe attachment avoidance will cry less often and have more negative attitudes toward crying. Atypical crying may also be related to somatization and MUSS severity because reduced crying and atypical attitudes toward crying may reflect the inability to experience distress in an emotional way. We, therefore, expected that the previously found association between attachment insecurity and MUSS severity [45] would be mediated by atypical crying behavior and/or attitudes. Furthermore, the relationships between MUSS severity, attachment, and empathy toward crying individuals were explored since previous research showed deficits in the ability to mentalize about others' emotions in MUSS patients [28].

\section{Method}

\section{Participants}

The sample consisted of 68 outpatients referred to the Department of Psychiatry of the Elisabeth-Tweesteden Hospital in Tilburg, the Netherlands, for treatment of somatic symptom disorder. Patients were eligible for this study if they were 18 years or older and were confirmed to reach criteria for somatic symptom disorder (SSD). Patients were diagnosed and selected by clinical interviews performed by a psychiatrist and psychologist. Criteria of SSD according to the DSM-V and other disorders were evaluated in order to determine comorbidity. Patients were excluded from participation when they met one of the following exclusion criteria: another comorbid diagnosis as the primary diagnosis, insufficient mastery of the Dutch language, and drug or alcohol abuse. The sample included patients with fibromyalgia, chronic fatigue syndrome, conversion disorder, migraine, headaches, chronic back pain, vertigo, gastrointestinal problems, and syncope. Patients were asked to participate in the study in person during their intake by their psychologist or by telephone by a research assistant. This study was approved by the Medical Ethics Committee of Brabant and by all institutes involved in the current study.

\section{Procedure}

After having signed an informed consent form, patients were invited by email to participate in the study. Participation consisted of completing an online survey either at home or at the hospital. Patients were asked to complete the survey before the start of treatment or within 3 weeks after the start of treatment. The survey collected information on demographical variables and consisted of questionnaires measuring attachment style, crying behavior, attitudes toward crying, the perception of crying on others, and physical functioning and pain (see Instruments section). Patients completed the survey within approximately 1 hour.

\section{Instruments}

\section{The Experiences in Close Relationships Revised Questionnaire (ECR-R)}

Attachment was measured using the ECR-R $[15,19]$. The ECR-R is a 36-item self-report questionnaire that measures 
adult romantic attachment on two 18-item dimensions: Attachment anxiety and attachment avoidance. Participants can indicate on a 7-point Likert scale ranging from 1 (strongly disagree) to 7 (strongly agree) how they experience their romantic relationships in general. An example of an item measuring attachment anxiety is "I often worry that my romantic partner does not really love me." An example of an item measuring attachment avoidance is "I prefer not to be too close to romantic partners." Internal consistencies were excellent (Cronbach's alpha $=0.90$ (anxiety), 0.91 (avoidance)).

\section{The RAND-36 Health Survey}

The RAND-36 was used in this study to measure MUSS severity and mental health problems, similar to a previous study with partly the same sample [45]. The RAND-36 is a 36-item self-report questionnaire that measures physical and mental health-related quality of life [53, 60]. Each item can be answered on a 0 to 100 scale ranging from (maximum impairment) to 100 (no impairment). The original questionnaire consists of 8 subscales. In this study, the "functional status" dimension was used to measure MUSS severity which consists of four subscales (19 items): Physical functioning, social functioning, emotional role limitations, and physical role limitations. Additionally, five items were used to measure mental health. The mental health scale correlates strongly with depressive symptoms [43] and was therefore used to as a measure for depressive symptoms to control for mental health problems. To create sum scores for the RAND-36, subscale sum scores had to be transformed using the algorithm from van der Zee and Sanderman ([60]; subscale sum score - minimum subscale sum score/score range $* 100)$. Internal consistency was good (functional status, Cronbach's alpha $=0.883$ ).

\section{Crying Frequency}

Frequency of crying was measured with the question: "How often did you cry in the past 4 weeks?" as published previously by Peter et al. [40].

\section{Awareness of the Interpersonal Impact of Crying}

Awareness of the interpersonal impact of crying was measured with the 7-item Crying and Coping questionnaire, which is part of the Adult Crying Inventory (ACI: [33, 55]). This questionnaire measures the awareness that one's crying behavior may have a substantial impact on other people and that it might be useful to cry in order to solicit attention and support from others (e.g., "When one cries, it does not leave other people unaffected"). Higher scores indicate a greater awareness that crying can be used to elicit attention and support from others. Items are scored on a 7-point Likert scale, ranging from "Strongly Agree" to "Strongly Disagree." Cronbach's alpha was 0.77 .

\section{Attitudes Toward Crying}

Attitudes toward crying were measured with the two subscales of the $\mathrm{B}$ dimension of the $\mathrm{ACI}$, measuring functions and emotions associated with crying: crying helps one feel better (4 items, e.g., "I feel relaxed after a good cry") and hatred of crying/negative attitudes toward crying (3 items, e.g., "I hate to cry"). Internal consistency was good (hatred of crying = 0.74 , crying helps one feel better $=.82$ ).

\section{Empathic Responses to Crying}

To measure the perception of the crying on others, a shortened version of the procedure of Vingerhoets et al. [57] and Riem, van IJzendoorn, De Carli, Vingerhoets, and BakermansKranenburg [44] was followed. Participants were shown eight pictures of four crying adults (two female, two male) and four crying infants in the survey. Participants were asked to rate each picture on five scales measuring empathic responses, ranging from 1 (strongly disagree) to 5 (neutral) to 9 (strongly agree): "This child/person needs to be comforted," "This child/person seems kind," "This child/person seems annoying," "I sympathize with this child/person," and "If I would be alone with this child/person, I would comfort her/him." Sum scores were calculated separately for the pictures of crying children and crying adults (children, $\mathrm{M}=32.00, \mathrm{SD}=$ 6.25 ; adults, $\mathrm{M}=27.41, \mathrm{SD}=5.60)$. The internal consistency of both sets of pictures was good (Cronbach's alpha children = 0.79, Cronbach's alpha adults $=0.77$ ).

\section{Statistical Analysis}

All analyses were performed with IBM SPSS Statistics 24 [27]. Pearson correlations between attachment styles, attitudes toward crying, interpersonal awareness of crying, crying frequency, and functional status were calculated. In addition, hierarchical regression analyses were performed to examine whether associations between crying attitudes and functional status remained significant after controlling for depressive symptoms, age, and sex. We controlled for depressive symptoms because depressive disorder was the most common comorbid disorder. Next, a mediation analysis was performed to test whether crying frequency or attitudes toward crying acted as a mediator in the relationship between anxious attachment and MUSS severity using bootstrapping methodology ( $=5000)$. The PROCESS macro from Preacher and Hayes [41] was used with age, sex, and depressive symptoms as covariates. 


\section{Results}

\section{Sample Characteristics}

We included 68 participants $(76.8 \%$ female, mean age $=$ 41.49), all diagnosed with SSD according to DSM-V criteria [2]. Of all participants, $51 \%$ had a comorbid disorder at the time of participation (anxiety, 4.4\%; depression, 34.3\%; PTSD, $5.8 \%$; personality disorders, $6.5 \%$ ). The majority of participants were unemployed $(70.59 \%)$ and used medication (79.42\%, pain medication, psychotropic medication, or other).

\section{Attachment, Crying Frequency, Crying Attitudes, and Functional Status}

The correlations between the variables are summarized in Table 1. A significant negative relationship between attachment anxiety and functional status was found, meaning that higher attachment anxiety was related to more severe MUSS. Additionally, a significant positive relationship was found between attachment avoidance and crying frequency, meaning that participants with higher attachment avoidance had cried significantly more often during the last 4 weeks. Furthermore, significant positive correlations were found between the dimensions "hatred of crying," anxious attachment, avoidant attachment, and crying frequency (see Table 1). More importantly, significant negative correlations were found between the dimensions "hatred of crying" and "awareness of interpersonal impact" and functional status, meaning that individuals with a poorer functional status reported more hatred of crying and were less aware of the interpersonal impact. See supplemental material (Figs. S1-S3) for scatterplots showing these associations. Hierarchical regression analysis showed that the associations between awareness of the interpersonal impact, hatred of crying, and functional status remained significant after controlling for sex, age, and depressive symptoms $(F(5,60)=7.25, p<0.001$, see Table 2$)$.

\section{Mediation Analysis}

Since the correlations pointed toward a relationship between the dimensions "hatred of crying," attachment anxiety, and functional status, mediation analyses were run with the dimension "hatred of crying" as the mediator while controlling for age, sex, and depressive symptoms. No significant indirect effect was found with attachment anxiety (see Fig. 1).

\section{Attachment, Functional Status and Empathic Reactions to Crying on Others}

The correlations between the variables are summarized in Table 3. No significant correlations were found between empathic reactions to crying adults, children, or both and attachment or functional status.

\section{Discussion}

The aim of the present study was to increase our understanding of emotional functioning in patients with MUSS. We studied crying behavior in these patients as this may increase our insight into the interpersonal difficulties and emotional dysfunctioning of this clinical group in everyday life. We examined associations between attachment, crying frequency (during the last 4 weeks), crying attitudes, and MUSS severity. According to our knowledge, this is the first study examining crying behavior in patients with MUSS. We found that MUSS severity was significantly related to attachment anxiety. In addition, MUSS severity was related to more negative attitudes toward crying. More specifically, patients with a lower level of functional status reported a more negative attitude toward crying and were less aware of the interpersonal impact of crying on others.

Our finding that patients with a lower level of functional status tend to have a more negative attitude toward crying may reflect their use of maladaptive strategies to regulate emotions.

Table 1 Mean (SD) of the self-report measurements and correlations between attachment anxiety, attachment avoidance, crying frequency, crying attitudes (hatred of crying/negative view toward crying, crying makes one feel better), and functional status

\begin{tabular}{|c|c|c|c|c|c|c|c|}
\hline & $\mathrm{M}(\mathrm{SD})$ & Attachment anxiety & $\begin{array}{l}\text { Attachment } \\
\text { avoidance }\end{array}$ & $\begin{array}{l}\text { Crying } \\
\text { frequency }\end{array}$ & $\begin{array}{l}\text { Hatred of } \\
\text { crying }\end{array}$ & Feel better & Functional status \\
\hline Attachment anxiety & $3.29(1.18)$ & & & & & & \\
\hline Attachment avoidance & $3.17(1.22)$ & 0.22 & & & & & \\
\hline Crying frequency & $4.29(5.11)$ & 0.03 & $0.34 * *$ & . & & & \\
\hline Hatred of crying & $4.16(1.70)$ & $0.39 * *$ & $0.26^{*}$ & $0.30 *$ & & & \\
\hline Feel better & $3.13(1.55)$ & -0.09 & -0.06 & 0.01 & -0.21 & & \\
\hline Functional status & $33.69(7.35)$ & $-0.48 * *$ & -0.21 & -0.20 & $-0.34 * *$ & 0.17 & \\
\hline Interpersonal impact & $3.38(1.10)$ & 0.13 & -0.04 & 0.01 & 0.20 & $0.44 * *$ & $-0.28 *$ \\
\hline
\end{tabular}

$* p<0.05$,

$* * p<0.001$ 
Table 2 Results of the hierarchical regression analysis with functional status as dependent variable and sex, age, and depressive symptoms as covariates in the first step and hatred of crying/negative attitude toward crying and awareness of interpersonal impact in the second step. $* p<0.05, * * p<0.01$.

Betas derived from the final block of the regression model

\begin{tabular}{lllll}
\hline & \multicolumn{2}{l}{ MUSS } & & \\
\cline { 2 - 5 } & $\mathrm{B}$ & $\mathrm{SE}$ & $\beta$ & $\mathrm{R}^{2}$ \\
\hline Step 1 & & & & $0.22^{* *}$ \\
Age & -0.20 & 0.21 & -0.10 & \\
Sex & -3.93 & 5.68 & -0.08 & 0.40 \\
Depressive symptoms & 0.63 & 0.17 & & $0.38^{* *}$ \\
Step 2 & & & $-0.19^{*}$ & \\
Hatred of crying & -2.59 & 1.43 & $-0.31^{* *}$ & \\
Awareness of interpersonal impact & -6.06 & 2.09 & & \\
\hline
\end{tabular}

Patients with MUSS often experience more negative emotions but lack emotional awareness and often suppress or avoid their emotions [54]. A negative view toward crying may be a reflection of this tendency to avoid emotions, which may, in turn, eventuate in heightened susceptibility to somatization and the experience of physical symptoms. This negative attitude toward crying may be rooted in experiences of rejection of inconsistent responding to signaled cues of distress during childhood. Indeed, reporting a negative view toward crying was also positively related to attachment anxiety, meaning that MUSS patients with an anxious state of mind with respect to attachment relationships reported more negative attitudes toward crying. A negative attitude toward crying, however, did not mediate the association between attachment anxiety and MUSS severity, possibly because other mediating factors, such as alexithymia [45], play a more important role in this association.

In contrast to our expectations, MUSS severity was not related to crying frequency. However, we found that crying frequency during the last 4 weeks was related to attachment avoidance in MUSS patients, with a higher crying frequency reported by more avoidantly attached patients. This is contradictory with previous findings, possibly due to differences in study populations. Previous studies with nonclinical populations found that higher levels of attachment avoidance were consistently related to crying less recently, less frequently, and to an overall lower crying proneness [4, 12, 31, 35]. Avoidantly attached individuals are usually able to inhibit

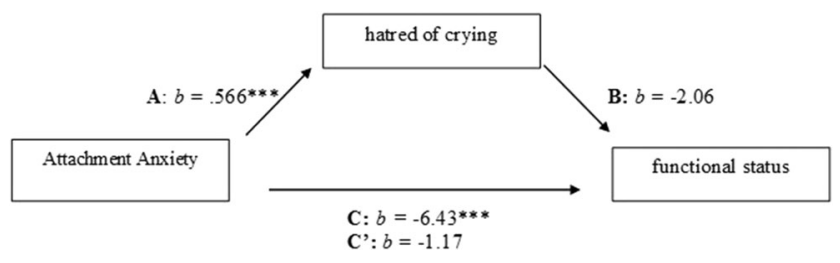

Fig. 1 Model depicting the direct and indirect effects of attachment anxiety on functional status using the dimension "hatred of crying/ negative attitude toward crying" as the mediator $(* * *=p<0.01)$ and suppress their emotional experience [59]. However, according to a study by Berant et al. [5], deactivating strategies such as suppressing emotions tends to collapse under demanding and stressful situations. As a result, the association between crying and avoidance may be different in clinical groups. Patients with MUSS often experience disruptions to their daily functioning due to chronic disabilities, such as prolonged periods of absence at work. This reduced quality of life, and the failure to find somatic explanations for their health problems may cause high levels of distress, and, as a result, these patients may, therefore, show different crying behaviors than healthy individuals with an avoidant attachment style. Moreover, it should be noted that the participating patients were about to start with their treatment program, which may further elevate levels of distress. Thus, frequent crying reported by MUSS patients with an avoidant attachment style may reflect a breakdown of deactivating strategies such as the inhibition of crying and expressions of sadness.

One more surprising finding in this study was that neither insecure attachment nor functional status was related to empathic reactions to crying on others in patients with MUSS. Since more severe MUSS and attachment insecurity have been linked to mentalization difficulties in previous studies $[28,42,50]$, it was expected that individuals with MUSS would experience difficulty in mentalizing about emotions of others as well. Mentalization can be described as the ability to reflect and interpret one's own and others' behavior in terms of internal emotional and mental states and relate to differentiate and categorize one's own and others' feelings, thoughts, and beliefs [18]. This capacity is developed through interaction with caregivers, if the child's emotional states are mirrored and labeled. Hence, it requires the context of secure attachment [13, 18]. Multiple studies indicate that patients with MUSS show mentalization deficits [23, 45, 32], possibly because these individuals received parental attention, care, or consolation in response to physical distress rather than to emotional distress during their childhood [38]. This might, in turn, lead to a tendency to experience emotional discomfort as physical discomfort and to difficulties in recognizing and labeling internal states. Mentalization of others' emotional 
Table 3 Correlations between empathic reactions toward crying adults, crying children, and both adults and children and the variables attachment anxiety, attachment avoidance, and functional status

\begin{tabular}{lllll}
\hline & M (SD) & $\begin{array}{l}\text { Attachment } \\
\text { anxiety }\end{array}$ & $\begin{array}{l}\text { Attachment } \\
\text { avoidance }\end{array}$ & $\begin{array}{c}\text { Functional status } \\
\text { Empathic reactions to crying children }\end{array}$ \\
Empathic reactions to crying adults & $32(6.2)$ & -0.01 & 0.01 & -0.07 \\
\hline
\end{tabular}

states may also play a role in MUSS. Mentalization of feelings, thoughts, and behavior of others is important in understanding and communicating effectively with them. The inability to mentalize about others' emotions, both affectively and cognitively, has been found to mediate the link between insecure attachment and difficulties in interpersonal relationships in patients with MUSS [28].

Koelen et al. [28] hypothesized that the interpersonal difficulties that individuals with MUSS often experience stem from reduced empathy toward others. For example, Peng et al. [39] showed reduced empathy toward somatic pain of others in patients with MUSS. Also, de Greck et al. [21] found disturbed emotional empathy and altered brain activity in regions related to emotional processing in patients with MUSS. The difference between our results and previous research on empathy in patients with MUSS might be that, in this study, we did not ask patients to label emotions correctly but only if they empathized with the tears of others. This might be a less complex skill than recognizing emotions, labeling them, and mentalizing about the reason why others cry. Stevens [52] found that anxiously attached individuals are more perceptive of emotions of themselves and others but experience difficulty in labeling those emotions. Interpersonal difficulties in patients with MUSS may, therefore, stem from mentalization difficulties related to understanding the emotions of others, rather than a lack of empathy per se. Indeed, our study indicates that MUSS patients have low awareness of the impact of crying on others, which may be a reflection of their interpersonal difficulties and deficits in emotion understanding.

The present study had some serious limitations that suggest directions for future research. Firstly, the data in this study is based on self-report measures. For example, crying behavior was measured by asking participants to report their crying frequency during the last 4 weeks. This might have led to social desirability, and some participants indicated not knowing their crying frequency. Future studies might induce crying in participants directly or might rely on clinical data to measure crying behavior more directly. Also, a diary study might give a more accurate reflection of crying behavior. Moreover, future studies should also include measurements of mentalization abilities as this may be related to crying behavior. Another limitation is that functional status was assessed with a general health questionnaire, similar to a previous study with partly the same sample [45]. It should be noted that the measure that we applied should be considered only a proxy for MUSS. Furthermore, the findings on the relationships between attitudes toward crying, attachment, and symptom severity were correlational, and the nature of the direction of these relationships can only be speculated. Finally, the majority of the participants in this study suffered from a comorbid psychiatric disorder or used psychotropic medication, which might have influenced the results.

To summarize, our study is the first to examine crying attitudes and behavior in MUSS patients. We found that MUSS patients report negative views of crying and low emotional awareness of the interpersonal impact of crying on others. These altered crying attitudes seem to stem from a history of insecure attachment experiences. Future studies on crying behavior in MUSS patients may shed more light on their emotional life and can potentially contribute to the further development of interventions. For example, therapeutic interventions could help these individuals in optimizing the conditions around crying. A more positive attitude toward crying and increased awareness of its impact on others may facilitate crying as a more functional coping mechanism, eliciting more support from others and reducing interpersonal difficulties (cf. [25]).

\section{Compliance with Ethical Standards}

Conflict of Interest The authors declare no conflicts of interest.

Ethics Statement All procedures performed in studies involving human participants were in accordance with the ethical standards of the institutional and/or national research committee (Medical Ethics Committee of Brabant) and with the 1964 Helsinki declaration and its later amendments or comparable ethical standards. All participants gave informed consent.

Open Access This article is distributed under the terms of the Creative Commons Attribution 4.0 International License (http:// creativecommons.org/licenses/by/4.0/), which permits unrestricted use, distribution, and reproduction in any medium, provided you give appropriate credit to the original author(s) and the source, provide a link to the Creative Commons license, and indicate if changes were made.

\section{References}

1. Ainsworth MD, Blehar M, Waters E, Wall S. Patterns of attachment. NJ: Erlbaum: Hillsdale; 1978. 
2. American Psychiatric Association. Diagnostic and statistical manual of mental disorders. 5th ed. Washington, DC: Author; 2013.

3. Barsky AJ, Orav EJ, Bates DW. Somatization increases medical utilization and costs independent of psychiatric and medical comorbidity. Arch Gen Psychiatry. 2005;62:903-10.

4. Bartholomew K, Horowitz LM. Attachment styles among young adults: a test of a four-category model. J Pers Soc Psychol. 1991;61(2):226-44.

5. Berant E, Mikulincer M, Shaver PR. Rorschach correlates of selfreported attachment dimensions: dynamic manifestations of hyperactivating and deactivating strategies. J Pers Assess. 2005;84(1):70-81.

6. Bowlby J. Attachment and loss. New York: Basic Books; 1969/ 1982.

7. Breuer J, Freud S. Studies on hysteria (1893-1895). In: Strachey J, editor. The standard edition of the complete psychological works of Sigmund Freud. London: Hogarth; 1955.

8. Bylsma LM, Vingerhoets A, Rottenberg J. When is crying cathartic ? An international study. J Soc Clin Psychol. 2008;27(10):1165-87.

9. Ciechanowski PS, Katon WJ, Russo JE, Dwight-Johnson MM. Association of attachment style to lifetime medically unexplained symptoms in patients with hepatitis C. Psychosomatics. 2002;43(3):206-12.

10. Cochrane CE, Brewerton TD, Wilson DB, Hodges EL. Alexithymia in eating disorders. Int J Eat Disord. 1993;14:219-22.

11. Cornelius RR. Toward a new understanding of weeping and catharsis? In: Vingerhoets A, Van Bussel F, Boelhouwer A, editors. The (non)expression of emotions in health and disease. Tilburg: Tilburg University Press; 1997. p. 303-22.

12. Denckla CA, Fiori KL, Vingerhoets AJJM. Development of the crying proneness scale: associations among crying proneness, empathy, attachment, and age. J Pers Assess. 2014;96(6):619-31.

13. Dykas MJ, Cassidy J. Attachment and the processing of social information across the life span: theory and evidence. Psychol Bull. 2011;137(1):19-46.

14. Drenger M, Mikulincer M, Berant E. Attachment orientations and adult crying. Psychoanal Psychol. 2017;34(3):311-21.

15. Fairchild AJ, Finney SJ. Investigating validity evidence for the experiences in close relationships-revised questionnaire. Educ Psychol Meas. 2006;66(1):116-35.

16. Feeney JA, Noller P. Attachment style as a predictor of adult romantic relationships. J Pers Soc Psychol. 1990;58(2):281-91.

17. Feeney JA. Adult romantic attachment: developments in the study of couple relationships. In: Cassidy J, Shaver PR, editors. Handbook of attachment: theory, research, and clinical applications. New York: Guilford Press; 2016. p. 456-81.

18. Fonagy P, Gergely G, Jurist EL, Target M. Affect regulation, mentalization, and the development of the self. New York: Other Press; 2002.

19. Fraley RC, Waller NG, Brennan KA. An item response theory analysis of self-report measures of adult attachment. J Pers Soc Psychol. 2000;78(2):350-65.

20. Frey WH, Langseth M. Crying: the mystery of tears. Minneapolis: Winston Press \& Harper Row. p. 174-80.

21. De Greck M, Scheidt L, Bo AF, Tempelmann C, Ulrich C, Stockum $\mathrm{E}$, et al. Altered brain activity during emotional empathy in somatoform disorder. Hum Brain Mapp. 2012;33:2666-85.

22. Gračanin A, Bylsma LM, Vingerhoets AJJM. Why only humans shed emotional tears. Hum Nat. 2018;29(2):104-33.

23. Gucht D, Heiser W. Alexithymia and somatisation: a quantitative review of the literature. J Psychosom Res. 2003;54:425-34.

24. Haller H, Cramer H, Lauche R, Dobos G. Somatoforme störungen und medizinisch unerklärbare symptome in der primärversorgung: Systematischer review und metaanalyse der prävalenzen. Dtsch Arztebl Int. 2015;112(16):279-87.
25. Hesdorffer DC, Vingerhoets AJJM, Trimble MR. Social and psychological consequences of not crying: possible associations with psychopathology and therapeutic relevance. CNS Spectr. 2017;23:414-21.

26. Hendriks MC, Croon MA, Vingerhoets AJ. Social reactions to adult crying: the help-soliciting function of tears. J Soc Psychol. 2008;148(1):22-42.

27. IBM Corp. Released. IBM SPSS Statistics for Windows, Version 24.0. Armonk: IBM Corp; 2016.

28. Koelen JA, Eurelings-Bontekoe LHM, Kempke S. Cognitive alexithymia mediates the association between avoidant attachment and interpersonal problems in patients with somatoform disorder. $\mathrm{J}$ Psychol. 2016;150(6):725-42.

29. Kolb LC. Attachment behavior and pain complaints. Psychosomatics. 1982;23:413-25.

30. Konnopka A, Schaefert R, Heinrich S, Kaufmann C, Luppa M, Herzog W, et al. Economics of medically unexplained symptoms: a systematic review of the literature. Psychother Psychosom. 2012;81(5):265-75.

31. Laan AJ, Van Assen MA, Vingerhoets AJ. Individual differences in adult crying: the role of attachment styles. Soc Behav Personal. 2012;40(3):453-71.

32. Luyten P, van Houdenhove B, Lemma A, Target M, Fonagy P. A mentalization-based approach to the understanding and treatment of functional somatic disorders. Psychoanal Psychother. 2012;26(2): $121-40$.

33. Mangweth B, Kemmler G, Ebner C, De Col C, Kinzl J, Biebl W, et al. The weeping behavior in anorexic and bulimic females. Psychother Psychosom. 1999;68(6):319-24.

34. McWilliams LA. Adult attachment insecurity is positively associated with medically unexplained chronic pain. Eur J Pain. 2017;21(8):1378-83.

35. Millings A, Hepper EG, Hart CM, Swift L, Rowe AC. Holding back the tears: individual differences in adult crying proneness reflect attachment orientation and attitudes to crying. Front Psychol. 2016;7:1003.

36. Nelson J'K. Seeing through tears: crying and attachment. New York: Psychology Press; 2005.

37. Nelson JK. An attachment perspective on crying in psychotherapy. In: Obegi JH, Berant E, editors. Attachment Theory and Research in Clinical Work with Adults. New York: The Guilford Press; 2009. p. 328-47.

38. Neumann E, Sattel H, Gündel H, Henningsen P, Kruse J. Attachment in romantic relationships and somatization. J Nerv Ment Dis. 2015;203(2):101-6.

39. Peng W, Meng J, Lou Y, Li X, Lei Y, Yan D. Reduced empathic pain processing in patients with somatoform pain disorder: evidence from behavioral and neurophysiological measures. Int J Psychophysiol. 2019;139:40-7.

40. Peter M, Arntz A, Klimstra T, Vingerhoets AJJM. Crying in borderline personality disorder patients. Psychiatry Res. 2019;273:100-7.

41. Preacher KJ, Hayes AF. Contemporary approaches to assessing mediation in communication research. In: Hayes AF, Slater MD, Snyder LB, editors. The sage sourcebook of advanced data analysis methods in communications research. Thousand Oaks: Sage; 2008.

42. Preis MA, Golm D, Kröner-Herwig B, Barke A. Examining differences in cognitive and affective theory of mind between persons with high and low extent of somatic symptoms: an experimental study. BMC Psychiatry. 2017;17(1):200.

43. Radloff LS. The CES-D scale: a self-report depression scale for research in the general population. Appl Psychol Meas. 1977;1(3):385-401.

44. Riem MME, van Ijzendoorn MH, De Carli P, Vingerhoets AJJM, Bakermans Kranenburg MJ. As tears go by: baby tears trigger more brain activity than adult tears in nulliparous women. Soc Neurosci. 2017;12(6):633-6. 
45. Riem MME, Doedée ENEM, Broekhuizen-Dijksman SC, Beijer E. Attachment and medically unexplained somatic symptoms: the role of mentalization. Psychiatry Res. 2018;268(May):108-13.

46. Reid S, Wessely S, Crayford T, Hotopf M. Secondary health care: retrospective cohort study. Br Med J. 2001;322:1-4.

47. Rottenberg J, Bylsma LM, Wolvin V, Vingerhoets AJJM. Tears of sorrow, tears of joy: an individual differences approach to crying in Dutch females. Personal Individ Differ. 2008;45(5):367-72.

48. Sitnikova K, Pret-Oskam R, Dijkstra-Kersten SMA, Leone SS, van Marwijk HWJ, van der Horst HE, et al. Management of patients with persistent medically unexplained symptoms: a descriptive study. BMC Fam Pract. 2018;19(1):88.

49. Soltis J. The signal functions of early infant crying. Behav Brain Sci. 2004;27(4):443-50.

50. Subic-Wrana C, Beutel ME, Knebel A, Lane RD. Theory of mind and emotional awareness deficits in patients with somatoform disorders. Psychosom Med. 2010;72(4):404-11.

51. Stuart S, Noyes R. Attachment and interpersonal communication in somatization. Psychosomatics. 1999;40(1):34-43.

52. Stevens FL. Affect regulation styles in avoidant and anxious attachment. Individ Differ Res. 2014;12(3):123-30.

53. Van der Zee KI, Sanderman R, Heyink JW, de Haes H. Psychometric qualities of the RAND 36-Item Health Survey 1.0: a multidimensional measure of general health status. Int J Behav Med. 1996;3(2):104-22.
54. Van Middendorp H, Lumley MA, Jacobs JWG, van Doornen LJP, Bijlsma JWJ, Geenen R. Emotions and emotional approach and avoidance strategies in fibromyalgia. J Psychosom Res. 2008;64: 159-67.

55. Vingerhoets A. Adult crying questionnaire (ISAC). Tilburg: Department of Psychology, Tilburg University; 1996.

56. Vingerhoets AJJM, Bylsma LM. The riddle of human emotional crying: a challenge for emotion researchers. Emot Rev. 2016;8(3): 207-17.

57. Vingerhoets AJJM, van de Ven N, van der Velden Y. The social impact of emotional tears. Motiv Emot. 2016;40(3):455-63.

58. Waller E, Scheidt CE. Somatoform disorders as disorders of affect regulation: a development perspective. Int Rev Psychiatry. 2006;18(1):13-24.

59. Wei M, Vogel DL, Ku T-Y, Zakalik RA. Adult attachment, affect regulation, negative mood, and interpersonal problems: the mediating roles of emotional reactivity and emotional cut- off. J Couns Psychol. 2005;52(1):14-24.

60. van der Zee, K.I., Sanderman, R., 2012. Het Meten Van De Algemene Gezondheidstoestand Met De RAND-36, Een Handleiding. UMCG/Rijksuniversiteit Groningen, Research Institute SHARE Tweede herziene druk.

Publisher's Note Springer Nature remains neutral with regard to jurisdictional claims in published maps and institutional affiliations. 